\title{
Imagens para instruir Estudo das estampas que compõem a edição portuguesa do livro de poemas As Plantas, de Ricardo de Castel ${ }^{1}$
}

\section{MARIA DE FÁTIMA MEDEIROS DE SOUZA}

medeiros_fatima@hotmail.com - Universidade de Brasília (UnB), Brasil

Fecha de recepción: 28 de octubre de 2017

Fecha de aceptación: 7 de diciembre de 2017

\section{RESUMO}

As estampas do gravador Romão Eloy de Almeida presentes na edição portuguesa do livro de poemas As Plantas de Ricardo de Castel são significativas como instrumentos de propagação dos valores defendidos pelos intelectuais luso-brasileiros do final do século XVIII. O livro de poemas foi impresso na Oficina Arco do Cego e se inscreve no conjunto de traduções que visavam promover a ascensão do nível educacional, cultural e econômico segundo os ideais iluministas. Sobressaem nas publicações científicas desse período, as obras de Botânica e os manuais destinados a instruir as práticas agrícolas. A tradução portuguesa da obra As Plantas se aproxima dessas publicações e se destaca por fornecer ao leitor os conhecimentos do mundo natural de forma aprazível.
PALAVRAS-CHAVE: Romão Eloy de Almeida, poesia didática, Iluminismo luso-brasileiro, Oficina tipográfica, calcográfica e literária do Arco do Cego.

\section{ABSTRACT}

The engravings of the engraver Romão Eloy de Almeida in the Portuguese edition of the book of poems The Plants of Ricardo de Castel are significatives as instruments for the propagation of the values defended by Luso-Brazilian intellectuals at the late eighteenth century. The book of poems was printed in Oficina Arco do Cego and is part of the set of translations aimed at promoting the rise of the educational, cultural and economic level according to the illuminist ideals. The works of Botany and the manuals to instruct agricultural practices stand out in the scientific publications of this period. The portuguese translation of the work The Plantscomes close to these publications and stands out for providing the reader with the knowledge of the natural world in a pleasant way.

KEYWORDS: Romão Eloy de Almeida, didactic poetry, Portuguese-Brazilian illuminism, Oficina Tipográfica, Calcográfica e Literária do Arco do Cego.

1 Uma versão desse artigo foi apresentada no IX Congresso Internacional de Teoria e História das Artes XVII-Jornadas CAIA, realizado em Buenos Aires, Argentina, entre os dias 27 e 30 de setembro de 2017. 


\section{INTRODUÇÃO}

A cultura científica em Portugal durante os séculos XVIII e XIX promoveu um volume significativo de publicações ${ }^{2}$. Um aspecto marcante nessa produção bibliográfica é a diversidade de tipologias textuais e imagéticas, presente tanto nas edições de caráter científico e prático quanto nas que aliam ciência e literatura. Para enfatizar os escritos que aliam poesia e ciência, este artigo trata das imagens produzidas pelo gravador português, Romão Eloy de Almeida (?-1822), para o poema As Plantas, de Ricardo de Castel (1758-1832) ${ }^{3}$. Eloy de Almeida esteve no Brasil em 1809 e alcançou certa proeminência entre artistas que formaram o grupo de gravadores da Oficina Tipográfica, Calcográfica e Literária do Arco do Cego (1799-1801). Alguns museus brasileiros guardam obras desse artista, caso da notória coleção da Biblioteca Brasiliana Guita e José Mindlin, da Universidade de São Paulo, e das obras que estão no acervo da Biblioteca Nacional do Rio de Janeiro. Nessas bibliotecas estão coleções de livros ilustrados, gravuras originais e um número significativo de traduções, dentre as quais se destacam as destinadas ao ensino das técnicas de gravuras e também os textos que buscavam promover o desenvolvimento de técnicas agrícolas nas colônias portuguesas.

As gravuras que ilustram o livro de Castel podem ser associadas às imagens das publicações que disseminavam os saberes ligados à agricultura, edições difundidas durante o século XVIII. Dessa forma, este artigo procura relacionar as ilustrações que acompanham o livro de Castel com a produção bibliográfica luso-brasileira, considerando o papel das imagens como difusoras das melhorias agrícolas e como propagadoras dos valores iluministas.

A Oficina Arco do Cego constitui um dos projetos empreendidos no contexto ilustrado português, durante o século XVIII, com vistas à disseminação do conhecimento científico, tido como um projeto essencial para o desenvolvimento econômico e cultural do reino lusitano. Algumas ações significativas que promoveram os estudos de história natural merecem destaque, uma vez que elas formam políticas de incentivo cultural que abriram caminho para outros avanços posteriores. É o caso do estímulo ao colecionismo bibliográfico, à produção tipográfica e ao ensino da gravura durante o reinado de D. João V (1689-1750). Também foram significativas as ações empreendidas por D. José I (1714-1777), que, por intermédio do Marques de Pombal (1699-1782), instituiu a Real Oficina Tipográfica. Essa oficina procurava suprir a demanda tipográfica do reino e da sociedade letrada, imprimindo obras clássicas a preços módicos. Da mesma forma, no reinado

2 Além disso, essa difusão dos estudos da história natural também repercutiu no Brasil, com o envio de expedições científicas e a publicação de textos do século XVI. Caso de obras como a Carta de José de Anchieta, escrita em 1560 e publicada em 1799; também a obra de Gabriel Soares de Souza, escrita em 1587 e editada em 1825 (Belluzzo, 1994).

3 Optamos por usar o nome Ricardo de Castel, pois é dessa forma que os portugueses se referem ao poeta francês, René-Richard Louis Castel. 
de D. Maria I (1734-1816), importantes instituições culturais foram estabelecidas, é o caso da Real Biblioteca Pública da Corte e da Oficina Tipográfica Arco do Cego ${ }^{4}$ (Marques, 2014).

No contexto luso-brasileiro, configuram como ações relevantes para o desenvolvimento científico a criação de espaços propícios para os estudos de história natural, especialmente daqueles ligados à botânica. Partindo da perspectiva de que esses lugares contribuiriam para o desenvolvimento econômico do reino lusitano, tornando-o mais próximo dos modelos francês e inglês. Associados à difusão da botânica, também se destacam o estabelecimento do Museu de História Natural e a criação da Academia Real de Ciências e do Real Jardim Botânico (Marques, 2014). Todas essas ações adotadas pelo reino português foram resultantes da crescente presença de naturalistas estrangeiros na península ibérica, assim como a incessante procura pelos elementos da natureza exótica dos outros continentes e a potencialidade econômica proveniente dessas viagens. Para os objetivos deste estudo, também convém pontuar a difusão de traduções portuguesas de obras proeminentes no contexto cultural europeu, como é o caso do poema As Plantas. Essas traduções se vinculavam a uma série de projetos do reformismo ilustrado que buscavam promover a educação e a cultura nas regiões que formavam o reino português $\mathbf{5}^{\mathbf{}}$.

\section{A PRODUÇÃO LIVRESCA LUSO-BRAZILEIRA E A PROPAGAÇÃO DOS SABERES LIGADOS ÂAGRICULTURA}

A obra de Ricardo de Castel ${ }^{\mathbf{6}}$ se insere num gênero literário típico do século XVIII, cujas raízes remetem à literatura clássica. Os "poemas didáticos", como esse gênero ficou conhecido, são peças literárias que pretendem conjugar poesia e ciência, com o objetivo de instruir e entreter. A associação entre história natural e escrita poética remonta á Virgílio (70-19 a. C.) e Horácio (65-8 a. C.). As Geórgicas, obras de Virgílio que versam sobre as belezas da natureza e do trabalho com a terra, forneceram um modelo para muitos poetas que se dedicaram ao gênero didático (Ménahèze, 2005).

Nas últimas décadas do século XVIII, houve uma intensa produção de livros ilustrados com teor científico, fenômeno que contribuiu com a disseminação dos conhecimentos sobre o mundo natural para um público vasto. Muitas dessas obras poéticas foram influenciadas pelos estudos sistematizados por Carl Lineu (1707-1778), acerca das formas de reprodução das plantase suas

4 A Oficina Tipográfica, Calcográfica e Literária do Arco do Cego funcionou entre 1799 e 1801 e foi criada pelo brasileiro frei José Mariano da Conceição Veloso (1742-1811). Oslivros publicados por essa tipografia procuravam contribuir para o crescimento econômico e industrial de Portugal e de suas colônias (Cunha, 2010).

5 Como assinala a pesquisa de Lee: “Usar a imagem como instrumento didático e informativo era uma estratégia comum em Portugal no século XVIII, aplicação do conceito iluminista do uso da ciência e da técnica para promover o bem-estar social" (2014, p. 289).

6 Esse poema foi publicado em 1797 e contou com cinco edições em francês até $1839(1797,1799,1802,1823)$ (Bernardo, 2013). 
nomenclaturas. As publicações sobre botânica, por exemplo, costumavam a aliar referências poéticas associadas às plantas com descrições das principais características das espécies, além dos seus usos medicinais e econômicos. Um pioneiro nesse tipo de "poema científico" ou "poema didático" foi o escritor espanhol Baltasar Gracián (1601-1658), que escreveu um poema sobre as estações do ano ${ }^{7}$. Sobre essa mesma temática, escreveu o célebre poeta inglês, John Milton (1608-1674). Nesse período, também é notável a repercussão do poema The Botanic Garden: A Poem in Two Parts de Erasmus Darwin (1731$1802)^{8}$. Obra editada em 1788 , e que apresenta descrições em versos sobre as formas de reprodução das plantas (Teute, 2000). Outra obra relevante é o poema The Temple of Flora, escrito por Robert Thornton (1768-1837), onde são apresentados versos relacionados às espécies escolhidas pelo autor. No contexto francês, do qual a obra de Castel provém, destacam-se, como expoentes do gênero didático, escritores como Jacques Delille (1738-1813), Jean-Antoine Roucher (1745-1794), Jean-François de Saint-Lambert (1716-1803) e François-Joachim de Pierre de Bernis (1715-1794). Como enfatizado por Bernardo (2013), esses escritores cultivaram a "poesia natural, cantando entusiasticamente a vida campestre, a beleza bucólica e os novos conhecimentos da natureza" (p. 97).

A poesia didática se notabilizou pelo uso dos recursos descritivos e pela abordagem de temas pastorais, exaltando a vida campestre, a agricultura e as transformações da natureza. Nesse sentido, a temática da poesia didática revela a influência da antiguidade, principalmente das Geórgicas ${ }^{9}$, na medida em que trata dos ciclos da natureza e das técnicas agrícolas a partir de uma perspectiva bucólica. A publicação desses poemas de Castel pela Tipografia Arco do Cego formava, junto às demais publicações que incentivavam a propagação das tecnologias agrícolas, um conjunto de livros voltados para a instrução e a propagação desses saberes. Nesse contexto, as imagens que ilustravam os livros contribuíam com a difusão dos objetivos da cultura ilustrada do universo luso-brasileiro do século XVIII. Esses aspectos podem ser notados na ilustração "Plantação e colheita do Indigoal" (figura 1), que ilustra $O$ fazendeiro do Brazil, obra organizada por Frei Veloso ${ }^{\mathbf{1 0}}$. Essa imagem mostra os momentos de preparação do solo, a plantação e a colheita do índigo, uma espécie usada na fabricação de pigmentos (Veloso, 1806).

7 Embora seja possível associar a obra Teogonia de Hesíodo (750-650 a. C.) como precursora do gênero (Bernardo, 2013).

8 Avô do naturalista britânico Charles Darwin (1809-1882).

9 Opoeta Jacques Delille, expoente da poesia didática notabilizou-se pela tradução de Virgílio para alíngua francesa. Sobressai o fato de que as Geórgicas tiveram grande repercussão, recebendo três edições entre 1769 e 1785.

10 Um conjunto de manuais quetrata desseinteresseé Ofazendeiro do Brazil, editado por Frei Veloso entre 1798 e 1806 e impresso na Officina de Simão Thaddeo Ferreira. Esse manual abrange um total de onze volumes dedicados às práticas agrícolas. Nesselivro, a produção imagética se destaca como uma ferramenta didática usada para informar os leitores sobre as melhores formas de trabalhar o solo (Veloso, 1806). 
Figura 1. M. L. R. Vianna. "Plantação e colheita do Indigoal”. Vol. II. Imprensa Régia, 1806.

O propósito de Frei Veloso com a edição de Ofazendeiro do Brazil era promover melhorias do índigo, cultivado no Rio de Janeiro por meio da instrução dos fazendeiros que trabalham com essa planta. A imagem acima contribui para esse objetivo na medida em que mostra os trabalhadores lavrando a terra com as ferramentas adequadas e apresenta três momentos do cultivo. Trata-se de uma ilustração que representa os usos das ferramentas sob ângulos que permitem identificá-las. Outra característica que merece ser mencionada, é presença de notas explicativas que acompanham as imagens. São trechos que esclarecem aspectos das gravuras e que ajudam o leitor a entender os mecanismos representados. Como ressalta PatacaeSchiavinato (2016) sobre as ilustrações da obra O fazendeiro do Brazil: "as imagens

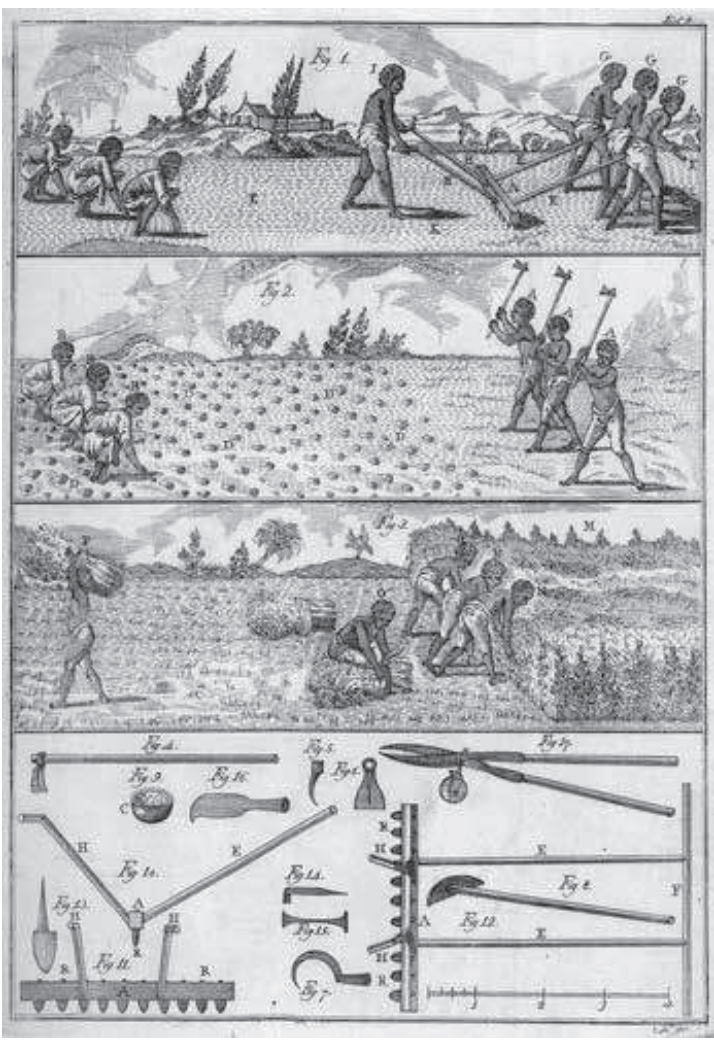

Fonte: Internet Archive. completavam ostextos, evice-versa, bem como simplificavam, porque sintetizavam processos de trabalhos, apresentação, montagem e usos de instrumentos coadunando-os com os trabalhadores" (p. 561).

A obra de Frei Veloso compartilha características com o poema de Castel. A principal delas é o destaque dado à agricultura, onde as imagens se apresentam como elementos essenciais para melhoria e o incentivo das práticas agrícolas. Também se observa a influência das obras francesas. Frei Velloso, por exemplo, se apropriou das informações e das imagens que ilustram a Encyclopédie sobre o cultivo do índigo (Diderot \& d'Alembert, 1751). Na verdade, tratam-se de cópias que visavam difundir o conhecimento sobre a agricultura para o público luso-brasileiro. De forma semelhante, As Plantas trata do esplendor do mundo natural e exaltam a agricultura. A tradução portuguesa da obra de Castel apresenta imagens copiadas da edição francesa, acompanhada de notas explicativas das estampas e contém informações sobre as técnicas agrícolas. O poema didático de Ricardo de Castel buscava difundir o conhecimento científico por meio dos recursos poéticos, a fim de tornar a ciência mais acessível e aprazível aos leitores. Essa obra pode ser considerada em conjunto com os demais livros editados na Oficina Arco do Cego que buscavam instruir um público vasto. A tradução desse poema, em 1801, se situa em um contexto de difusão de traduções portuguesas de títulos da literatura científica europeia do século XVIII. 


\section{AS IMAGENS QUE COMPÕEM A EDIÇÃO PORTUGUESA DO POEMA AS PLANTAS}

A edição portuguesa do poema de Castel apresenta um texto bilíngue, com o poema original em francês e a tradução para o português feita por Manuel Maria Barbosa Du Bocage (1765-1805). Bocage também traduziu outras obras de teor científico e poético, como os títulos O Consórcio das Flores (1801), de Demetrius de LaCroix, e Os jardins ou a Arte de Aformosear as Paizagens (1800), de Delille. Essas obras também foram editadas na Oficina Arco do Cego e apresentam projeto gráfico semelhante ao encontrado na edição de $A s$ Plantas. A obra de LaCroix, inclusive, é ilustrada com duas gravuras feitas por Romão Eloy de Almeida, o mesmo artista que ilustrou a obra de Castel. Todos esses livros traduzidos por Bocage se associam ao gênero da poesia didática $\mathrm{e}$ é notável a aproximação temática desses títulos.

OpoemaAsPlantas apresenta as nomenclaturascientíficas segundo o sistema de Lineu e cita as localidades das espécies mencionadas. Foram acrescentados na tradução portuguesa os nomes vernáculos para a flora e a fauna usados em Portugal. Esse cuidado do poema em instruir os leitores se alinha com as políticas implementadas pelo reformismo ilustrado português, nas quais se nota uma marcante presença de publicações francesas. Vale lembrar que a Oficina Arco do Cego é um dos empreendimentos resultantes dessa política, e que, embora tenha funcionado por um curto período de tempo, entre 1799e 1801, essa tipografia editou um total de 83 títulos, dentre os quais 45 traduções. A intenção de promover a tradução de obras com temáticas ligadas à história natural, como já explicitado, apresenta-seemummomentoem quePortugalimplementa uma sériedemedidas para disseminar o conhecimento científico no país (Harden, 2011).

No prefácio do poema de Castel, Bocage enumera uma série de cumprimentos ao reino de Portugal, enfatizando que a tradução de uma obra célebre como As Plantas é uma benesse ao público leitor, que apreciará em um só livro as maravilhas do mundo natural e a escrita poética. Essa forma de apresentação da obra ao público constitui um mecanismo retórico que procurava persuadir os leitores da relevância das traduções de obras científicas. Vale ressaltar que essas obras dos iluministas foram recebidas em Portugal com ressalvas, havendo por parte dos editores uma constante negociação para justificar a relevância de certas publicações científicas. Sobre as traduções da Oficina Arco do Cego, Harden afirma:

Por se manterem obedientes às regras que regiam a sociedade lusitana da época, os tradutores responsáveis por verter os paradigmas científicos iluminados para a língua portuguesa foram capazes de conectar discursivamente o tradicional e o novo. Estabeleceram um espaço texto entre o antigo regime português e os princípios do Iluminismo, transportando para o papel o poder que, no 'mundo real', pertencia a agentes sociais como censores e representantes do governo, ou seja, o poder de determinar o que as pessoas deveriam e/ou poderiam ler e/ou traduzir, e o que deveria ser proibido ou evitado (2011, p. 306). 
O caráter didático da obra de Castel pode ser identificado na forma com que ele combina aspectos práticos do cultivo das plantas com elementos de erudição científica e cultura humanística. Esse caráter didático pode ser notado, por exemplo, nos momentos em que Castel alerta sobre as pragas que assolam certas espécies ou quando o autor trata do cultivo do solo e das melhores épocas para se plantar. Todas essas informações são combinadas com citações mitológicas e descrições das principais características das plantas. Esses elementos narrativos buscavam educar os leitores partindo do pressuposto de que essa instrução poderia contribuir para o progresso econômico e material.

Com relação aos aspectos materiais do livro, a edição portuguesa do poema As Plantas foi impressa em formato in-octavo, com 19 centímetros de altura ${ }^{11}$. Parte das publicações dessa oficina eram impressas em pequenas dimensões, formato portátil e econômico tendo em vista a finalidade prática das obras. Como essas edições visavam um público amplo, a praticidade do formato in-octavo e a economia dos materiais fizeram com que algumas tipografias portuguesas da segunda metade do século XVIII passassem a adotar esses formatos reduzidos para imprimir manuais científicos (Pataca \& Schiavinatto, 2016).

A edição portuguesa dos versos de Castel apresenta poucos elementos decorativos, salvo os ornamentos da folha de rosto e os que adornam os conjuntos de versos referentes às quatro estações do ano. O texto impresso ocupa 181 páginas e apresenta imagens copiadas da publicação francesa de 1799 (a primeira edição de 1797 não foi ilustrada). As imagens estão dispostas em páginas separadas do texto e ilustram cada uma das quatro estações cantadas no poema. A técnica usada nessas gravuras é a do talho-doce, técnica de gravação direta, que usa ferramentas pontiagudas como buril, ponta-seca, berceau e roulette para encavar a matriz de cobre, método amplamente usado nos livrosilustrados da Oficina Arco do Cego.

Embora a técnica do talho-doce fosse reservada às imagens com poucos elementos e dimensões maiores, como prescreve Abraham Bosse (1602-1676), foi uma técnica explorada com esmero por Eloy de Almeida em ilustrações científicas, retratos e documentos cartográficos (Bosse, 1801; Ferreira, 1994) ${ }^{\mathbf{1 2}}$. Também é importante mencionar que a Oficina Arco do Cego procurou imprimir textos destinados a apurar os conhecimentos das técnicas de gravação em metal, até então tida como a que melhor se prestava à impressão de imagens mais detalhadas para os livros de história natural. Alguns desses manuais merecem destaque, caso das traduções de obras francesas como Princípios da arte da gravura, de Gerard Lairesse e Tratado de Gravura em água-forte, de Bosse.

11 Dados referentes ao exemplar da Biblioteca Brasiliana Guita e José Mindlin, da Universidade de São Paulo.

12 As pranchas da edição francesa de 1799 indicam a autoria das gravuras e do desenho por meio das seguintes inscrições: J. E. Deseve del', para o criador do desenho e Pierron sculp', para o gravador da matriz de cobre. Além dessas marcações, não há dados mais específicos sobre os artistas que fizeram essas ilustrações, o que dificulta a atribuição de autoria às imagens que compõem a edição francesa (Castel, 1799). 
Assim como a edição francesa, a tradução portuguesa da obra As Plantas apresenta uma descrição pormenorizadas das cinco ilustrações, evidenciando mais uma vez a sua finalidade de desenvolver nos leitores apreço e conhecimento sobre o mundo natural:

O Homem (disse comigo) he destinado a lavrar a Terra, isto hé, a cultivar as Plantas; mas perdas reiteradas o fazem conhecer, que o suor não basta, e que a mesma experiência pede instrupção. Mormente na jardinagem, onde, mais; varia a cultura, hé que se prova semelhante verdade. Cumpre, pois, em hum Poema como este, unir a teoria á practica, ou, por outras palavras, ligar o estudo das plantas com o trabalho que as tem por objecto. Reflecti igualmente que havia no Anno quatro grandes Épocas: Primavera, Estio, Outomno e Inverno; pelas quaes a Natureza distribue diversas producções; e conclue, que devia, imitando-a, dividirem quatro partes os estudos, e lidas relativas a tais producçóes (Castel, 1801, p. III).

Tratar dos ciclos da natureza, forma encontrada no poema de Castel, é uma estrutura comum aos poemas ligados ao gênero didático. Esse tema foi tratado por outros escritores franceses do mesmo período, como: Les Mois (Os Meses), de Roucher; LesSaisons(AsEstações), deSaint-LamberteLes QuatreSaison(Asquatro estações), de Bernis. Astemáticas relacionadas aosjardins eàs plantas também figuram como interesse para esses escritores (Ménahèze, 2005). No universo cultural português do século XVIII é significativa a tradução desse tipo de poema, justamente pelo fato dessa obra combinar aspectos práticos e eruditos.

A imagem que ilustra o frontispício da obra de Castel mostra o busto do naturalista Carl Lineu circundado por uma floresta onde animais e plantas oriundos de diferentes continentes convivem em um mesmo ambiente. Essa estampa apresenta como legenda um dos versos do poema de Castel "Tudo tu conheceste, e ensinas tudo" (Castel, 1801, p. 89), ao centro encontra-se o título C. Linee, à esquerda a assinatura do gravador Eloy de Almeida, Elö̈sculp, è̀ direita a Tipografia onde a imagem impressa, no Arco do Cego. A guirlanda que adorna o busto de Lineu é formada pelas flores da Linnaea borealis, espécie cujo nome homenageia o naturalista (figura 2).

Figura 2. Romão Eloy de Almeida. "Frontispício".

Calcogravura. Tipografia Arco do Cego, 1801. Fonte: Biblioteca Brasiliana Guita e José Mindlin. 
Naúltima décadadoséculoXVIII, há um movimento encabeçado por naturalistas franceses, do qual fazia parte o brasileiro José Bonifácio de Andrada (1763-1838), que solicitou a construção de um busto em homenagem ao naturalista Carl Lineu. Bonifácio foi um devedor das teorias do naturalista sueco e pretendia, junto de seus companheiros, "homenagear Lineu como autor de textos fundamentais sobre a 'economia da natureza"' (Kury, 2004, p. 114). A obra de Lineu pretendia marcar uma nova era de estudos de Botânica, e as imagens contribuíram com a disseminação de suas ideias. Exemplo disso é a imagem que ilustra o frontispício da obra "Hortus Cliffortianus" (1737), na qualumbusto do deus Apolo é representado com as feições de Lineu cercado por figuras alegóricas e elementos representativos dos quatro continentes (Daston \& Galison, 2007) (figura 3).

Figura 3. Jan Wandelaar. Alegoria da Botânica reformada (Frontispício). "Hortus Cliffortianus", 1737. Fonte: Biodiversity Heritage Library

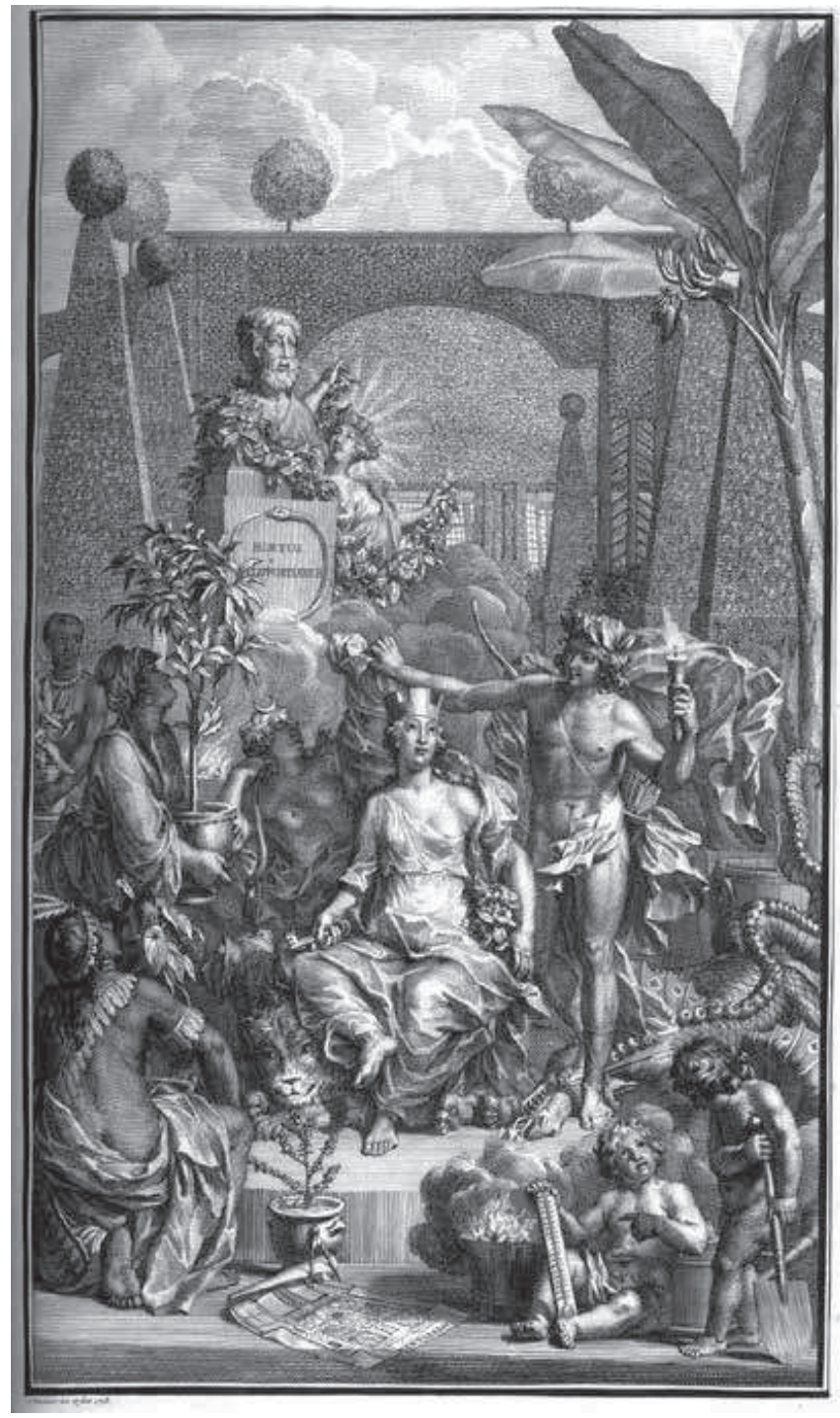

A novidade do frontispício da obra "Hortus Ciffortianus" é a introdução da figura de Lineu enfatizada como um reformador. O sistema classificatório desse naturalista pretendia inaugurar uma nova forma de estudar a Botânica, sendo adotado em parte significativa das publicações científicas desde seu estabelecimento. Os demais elementos da composição desse frontispício remetem aos livros de Botânica do século XVI, que passaram a trazer representações dos quatro continentes por meio de plantas e de objetos característicos de cada localidade (Shirley, 2008). É importante ressaltar que o método desenvolvido por Lineu coexistia com outros sistemas classificatórios e que essa propaganda contribuiu para o estabelecimento da sua taxonomia como o principal método de ordenação dos seres vivos partir do século XIX (Castel, 1801; Kury, 2004).

Essas homenagens prestadas à Lineu nas publicações século XVIII se aproximam, de um modo geral, da configuração apresentada na obra "Hortus 
Cliffortianus". O frontispício da obra de Castel, por exemplo, mostra elementos representativos dos quatro continentes e o busto de Lineu em destaque. A publicação de obras difusoras do sistema de Lineu se associa aos interesses da cultura científica difundida pelo reino lusitano, e, como destacado neste texto, a edição ilustrada do poema de Castel se apresenta como parte dessa política. No contexto português, convém salientar, que a promoção das teorias de Lineu foi defendida por Domenico Agostinho Vandelli (1735-1816), naturalista que desenvolveu um trabalho significativo de divulgação das obras do naturalista sueco.

Além da homenagem prestada à Lineu, outros aspectos da imagem do frontispício da obra de Castel são significativos. Há, por exemplo, a representação dos reinos vegetal, mineral e animal, de modo a sugerir uma apresentação concisa da natureza. Nos primeiros planos da imagem, destacam-se as espécies exóticas, de modo que os elementos representativos dos continentes asiático, africano e americano são privilegiados ante os do continente europeu. A escolha das espécies que compõem esse frontispício também não é fortuita, algumas plantas e animais se destacam pela utilização econômica e medicinal. Exemplo disso é o destaque ao cervo asiático, espécie que fornece o almíscar, uma substância largamente empregada na perfumaria. A representação do papiro também é notória, uma vez que essa planta de origem africana já foi um dos principais suportes usados na escrita (Castel, 1801).

Ao enfatizar as espécies exóticas e a diversidade da natureza, a ilustração do frontispício do poema de Castel elogia os conhecimentos resultantes das grandes navegações. Na segunda metade do século XVIII, importantes viagens de circunavegação foram empreendidas pelos europeus. Nesse período, houve um aumento das espécies exóticas coletadas e catalogadas. Também se consolidaram importantes espaços responsáveis por classificar, conservar e estudar essas coleções naturais, com destaque para a promoção de coleções dos museus de história natural e dos jardins botânicos (Thomas, 2010). Além disso, a configuração geral do frontispício se assemelha aos escritos científicos ilustrados que, de um modo geral, procuravam realçar a diversidade do mundo natural. No contexto lusitano, destaca-se a "Viagem Philosofica", liderada por Alexandre Rodrigues Ferreira (1756-1815), que percorreu o interior do Brasil constituindo uma coleção de objetos etnográficos e de imagens que ilustravam a flora e a fauna brasileira. Essa expedição perdurou cerca de dez anos, de 1783 a 1793, e constituiu um dos maiores projetos organizados pelo reino de Portugal para o mapeamento do interior do território brasileiro. A viagem de Ferreira ocorreu pouco tempo antes da tradução do poema de Castel e do conjunto de títulos editados pela Oficina Arco do Cego. A "Viagem Philosofica" mostra o interesse de Portugal em constituir um acervo significativo de peças relacionadas aos modos de vida dos povos indígenas, bem como da fauna e da flora da colônia (Belluzzo, 1994). 
As outras estampas que constam no livro As Plantas fazem referência às quatro estações do ano e apresentam vegetações correspondentes a essas fases. Essas gravuras, assim como a do frontispício, exibem aspectos representativos da poesia didática. São elementos que realçam a manufatura o desenvolvimento de tecnologias e as melhorias agrícolas. Em sentido mais amplo, os poemas didáticos tratam do controle do mundo natural obtido pelo trabalho constante e pela busca de novos conhecimentos. Por isso a divulgação das descobertas proporcionadas pelas expedições científicas figura como tema de interesse. Lembrando que o sistema de Lineu convém a esse propósito na medida em que possibilitou a internacionalização do conhecimento ${ }^{13}$. Outra temática recorrente é a importância dos jardins para o conhecimento das propriedades econômicas e medicinais das plantas. Consequentemente, a produção imagética atrelada a essa literatura costuma retratar a narrativa do domínio do mundo natural por meio de desenhos que permitem o reconhecimento das espécies retratadas, que evidenciem as tecnologias agrícolas (estufas, arados) eque mostrem a sistematização da natureza operada pelo conhecimento científico. Esses elementos estão presentes nas gravuras que ilustram a obra de Castel, como convém descrever a seguir.

A imagem que ilustra o "Canto I" (figura 4) traz elementos característicos da primavera. A cena representada mostra o momento em que uma criança interpela seus pais com ramos de plantas medicinais nas mãos. Abaixo da ilustração encontra-se um verso do poema: "Vê como nos ajuda o teu filhinho" (Castel, 1801, p. 31), que serviu de inspiração para essa imagem. Os versos de Castel indicam que as plantas que a criança entrega aos pais são a solda real (sanicula europaea) e a centaurea (centiana centaurium) $)^{14}$, espécies tradicionalmente conhecidas pelos seus usos medicinais. No primeiro plano, encontram-se alguns animais e plantas floridas; no plano posterior, a representação de uma vegetação rasteira; e, ao fundo, um dia parcialmente claro. Essa estampa do "Canto I" pode sugerir a importância do conhecimento das propriedades das plantas que é adquirido por meio da observação do mundo natural desde a tenra idade. Por isso a astúcia da criança é realçada. Pouco antes do verso associado à cena retratada na gravura, Castel destaca que ainda jovem preferia contemplar os jardins às construções palacianas francesas. Nesse sentido, a cena também pode sugerir a importância dos jardins para o estabelecimento dos estudos das potencialidades econômicas e medicinais das plantas (Castel, 1801).

13 Como mencionado anteriormente, a obra de Lineu foi propagada em Portugal por Domenico Vandelli, Manual de termos técnicos da história natural extraídos da obra de Lineu, publicada em 1788, ricamenteilustrado com gravuras em metal (Belluzzo, 1994; Kury, 2004).

14 Respectivamente, o nome popular e a nomenclatura da planta a partir do sistema criado por Carl von Lineu (Linnean Herbarium, 2017). 
Figura 4. Romão Eloy de Almeida. "Canto I". Calcogravura. Tipografia Arco do Cego, 1801.

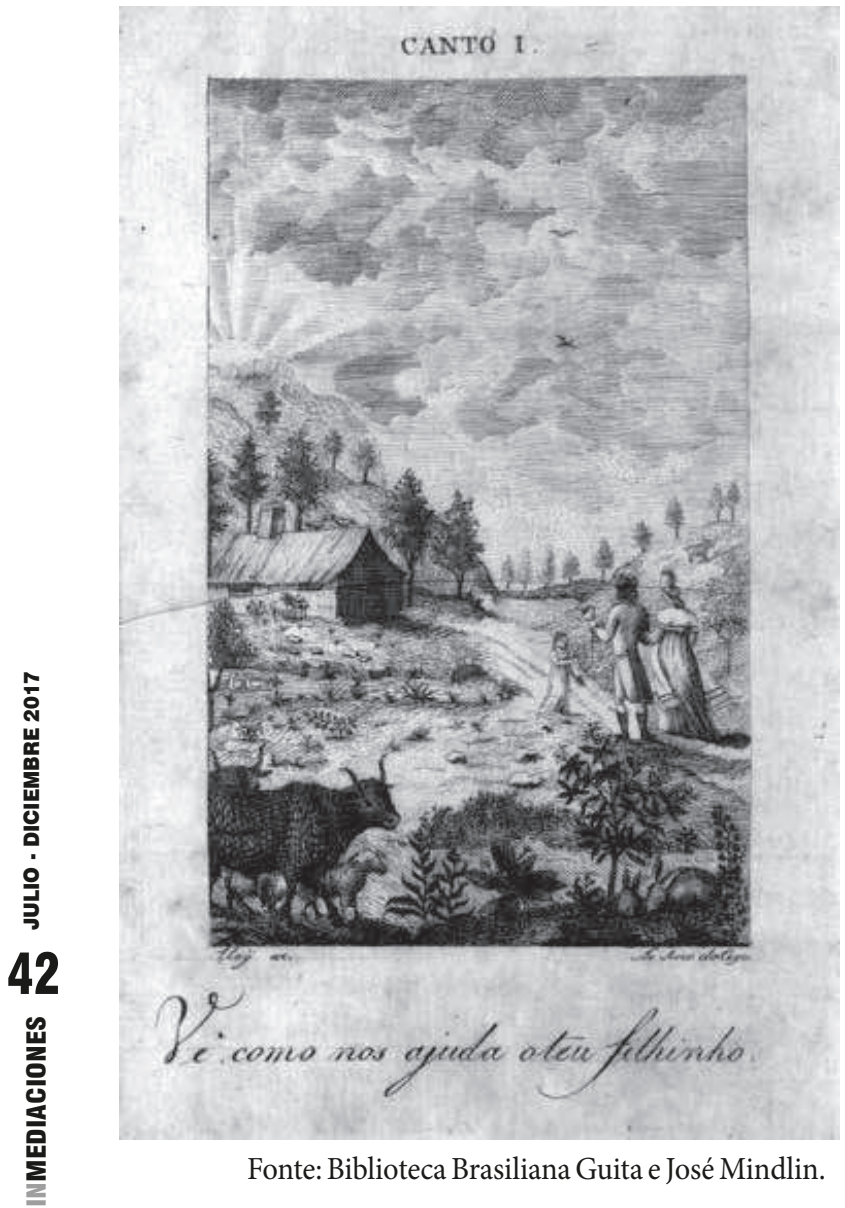

Figura 5. Romão Eloy de Almeida. "Canto II". Calcogravura. Tipografia Arco do Cego, 1801.

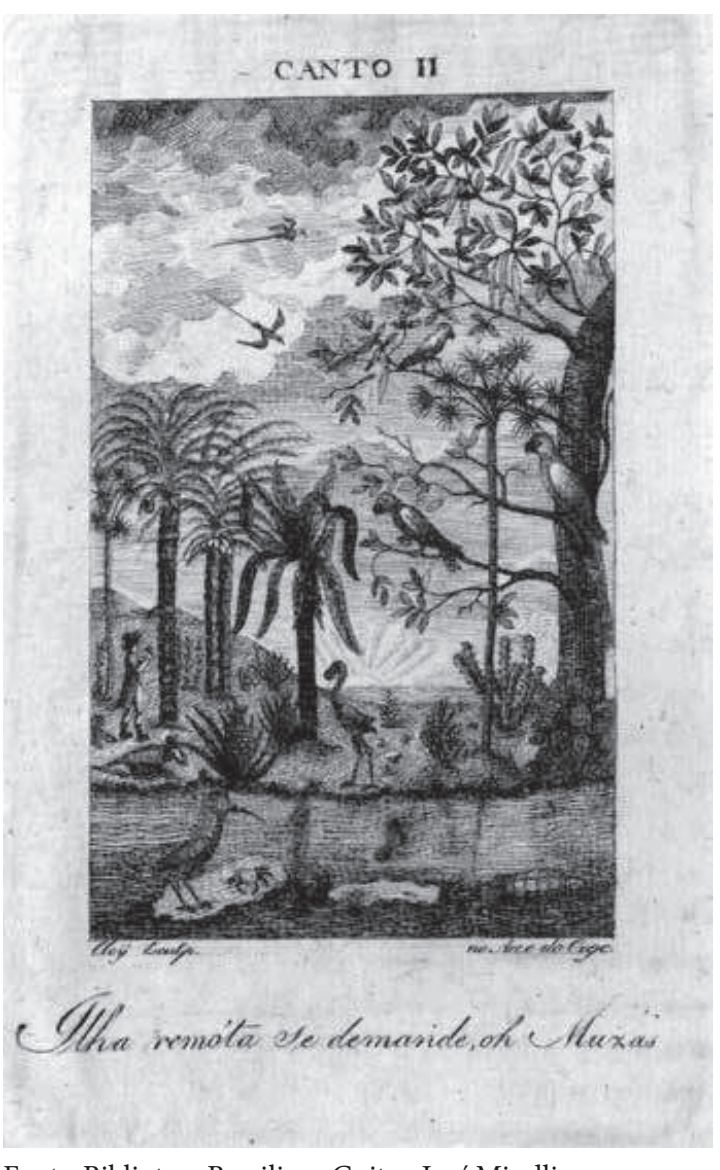

Fonte: Biblioteca Brasiliana Guita e José Mindlin.

A ilustração do "Canto II" (figura 5) é relativa ao verão e apresenta a Zona Tórrida, região situada entre os trópicos de Câncer e de Capricórnio, com elementos ligados ao bioma típico dessa localidade. O clima dessa região é predominantemente quente, e, embora haja uma diversidade de vegetações, a mais característica é a floresta tropical. Com a sua fauna e flora numerosa, as florestas tropicais são exaltadas pelo poema de Castel. Também é nesse canto que ele cita a maior quantidade de espécies. A ilustração desse poema apresenta a vista de uma ilha com plantas carregadas de frutos e habitada por diversos animais, a fim de realçar a diversidade da região topical e a profusão da natureza intensificada no verão. Se, no poema sobre a primavera, Castel destaca a época da floração das plantas, no verão, os frutos são enfatizados. Predomina também a citação ao sol como o promotor da transformação do mundo natural, astro rei que comanda os ciclos. A estampa mostra, em meio a essa erma e longínqua floresta, a imagem de um naturalista que observa a natureza ao seu redor a fim de estudá-la. Logo abaixo da imagem lê-se: "Ilha remota se desmande, oh musas" (Castel, 1801, p. 61), primeiro verso de uma sequência que introduz o tema da diversidade da natureza e enfatiza as florestas intocadas e pouco conhecidas dos europeus (Castel, 1801). 
O "Canto III" (figura 6) é o que trata do outono. A ilustração desse poema traz uma construção típica da região da Normandia, rodeada por um jardim onde estão dispostas pequenas plantas e, ao fundo, vislumbra-se a colheita da maçã. Abaixo da imagem segue a citação do verso: "Já do tronco abanado os frutos chovem" (Castel, 1801, p. 121), para enfatizar que a cena representada se refere ao momento da colheita dos frutos. Ao longo desses versos sobre o outono, Castel fala da dispersão das sementes, das plantas que brotam, da polinização; enfim, o autor discorre sobre o ciclo natural das plantas. $\mathrm{O}$ poeta também enfatiza mais uma vez o trabalho incessante do homem em cultivar a terra alertando: "Se descansar o arado, em breve os trigos deixarão de reinar nos úteis sulcos" (Castel, 1801, p. 99). Nesse canto sobre o outono há recomendações sobre a organização das plantas nas estufas, sobre as formas de cultivar as hortaliças e sobre a introdução de plantas exóticas na Europa (Castel, 1801).

Algumas questões são suscitadas a partir da descrição das imagens que acompanham os três primeiros cantos do poema de Castel, especialmente se partirmos da perspectiva de que a tradução portuguesa dessa obra pretendia divulgar alguns valores defendidos pela cultura científica do século XVIII. Nesse contexto, as ilustrações serviam para convencer, por exemplo, da diversificação da agricultura e da introdução de novas espécies nos museus de história natural. Uma preocupação frequente entre os intelectuais atuantes em Portugal, muitos dos quais brasileiros, era a necessidade de diversificar a produção agrícola no Brasil. A temática dos livros editados pelo Frei Veloso reflete esse interesse. Há uma predileção pela impressão de manuais e de tratados destinados a difundir conhecimentos práticos sobre a agricultura. Os manuais impressos pela Oficina Arco do Cego eram destinados a propagar novas plantações, difundir técnicas eficientes para o cultivo da natureza e incentivar o trabalho agrícola cuidadoso e sistemático ${ }^{15}$ (Wegner, 2004; Pataca \& Schiavinatto, 2016). Esses temas são

15 Contrariando os esforços empreendidos pela Oficina Arco do Cego, a recepção do público a esses livros foi apática. Grande parte dos livros não foram comprados, muitos permaneceram nos estoques enquanto outras remessas eram incessantemente enviadas às principais capitanias brasileiras, como Bahia, Pernambuco, Rio de Janeiro e São Paulo. Essa falta de interesse se deu pelo alto índice de analfabetismo da colônia e pela falta de um público para esse tipo de publicação (Wegner, 2004).

Figura 6. Romão Eloy de Almeida. “Canto III”. Calcogravura. Tipografia Arco do Cego, 1801.

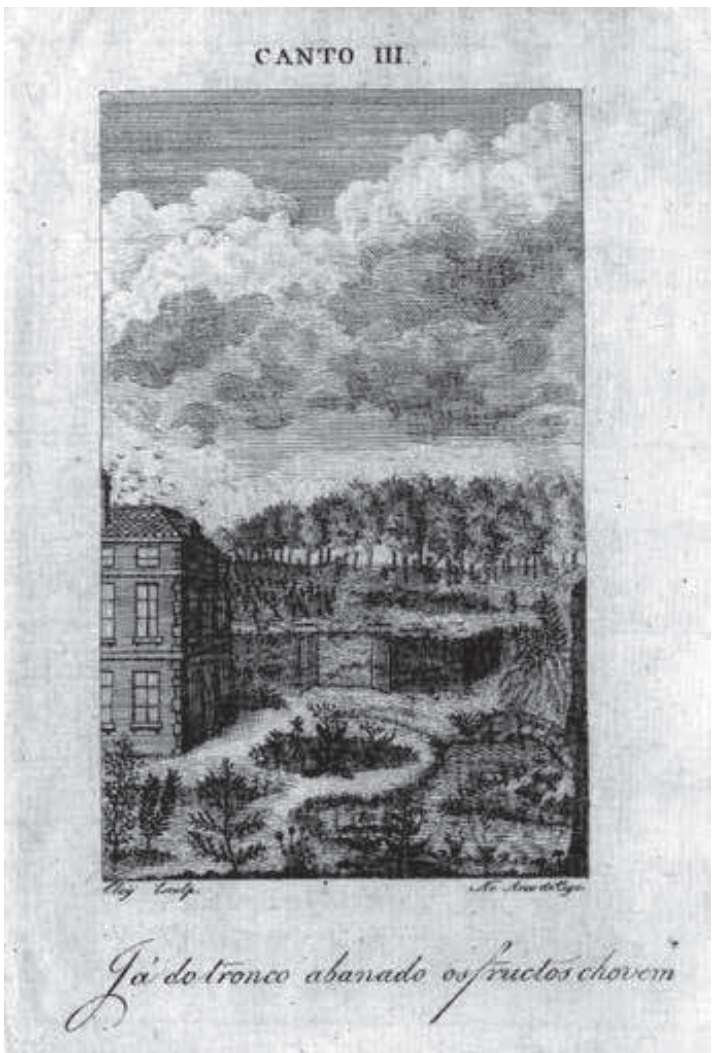

Fonte: Biblioteca Brasiliana Guita e José Mindlin. 
amplamente desenvolvidos nos versos de Castel, e, nesse sentido, as estampas usadas na ilustração desse volume configuram uma ferramenta de disseminação desses valores.

A ilustração que acompanha o "Canto IV" (figura 7), último poema dolivro de Castel, apresenta uma série de pequenos arbustos e plantas em primeiro plano, em sequência, a cena de um homem que se dirige a uma estufa e, ao fundo, a representação de uma floresta de pinheiros e de árvores de grande porte. As estufas são construções que mantem o calor e controlam o ambiente para que as plantas mais sensíveis às baixas temperaturas possam se desenvolver. A imagem parece sugerir que o engenho humano, mesmo nas condições mais adversas, pode desenvolver tecnologias para fazer florescer as plantas. Essa leitura é corroborada pela explicação da estampa, que enfatiza: "Huma estufa cheia de plantas em plena vegetação; tudo denota que a natureza se liga com a indústria humana para aformosear até os gelos do inverno" (Castel, 1801, p. XV). Se no inverno predominam as árvores em decadência e as folhagens esmaecidas e sem vida, essa estação também esconde plantas em semente e a vida em potência. O inverno também possui as suas belezas, e a respeito delas Castel enumera algumas vegetações que tornam essa estação mais aprazível. Nesse sentido,

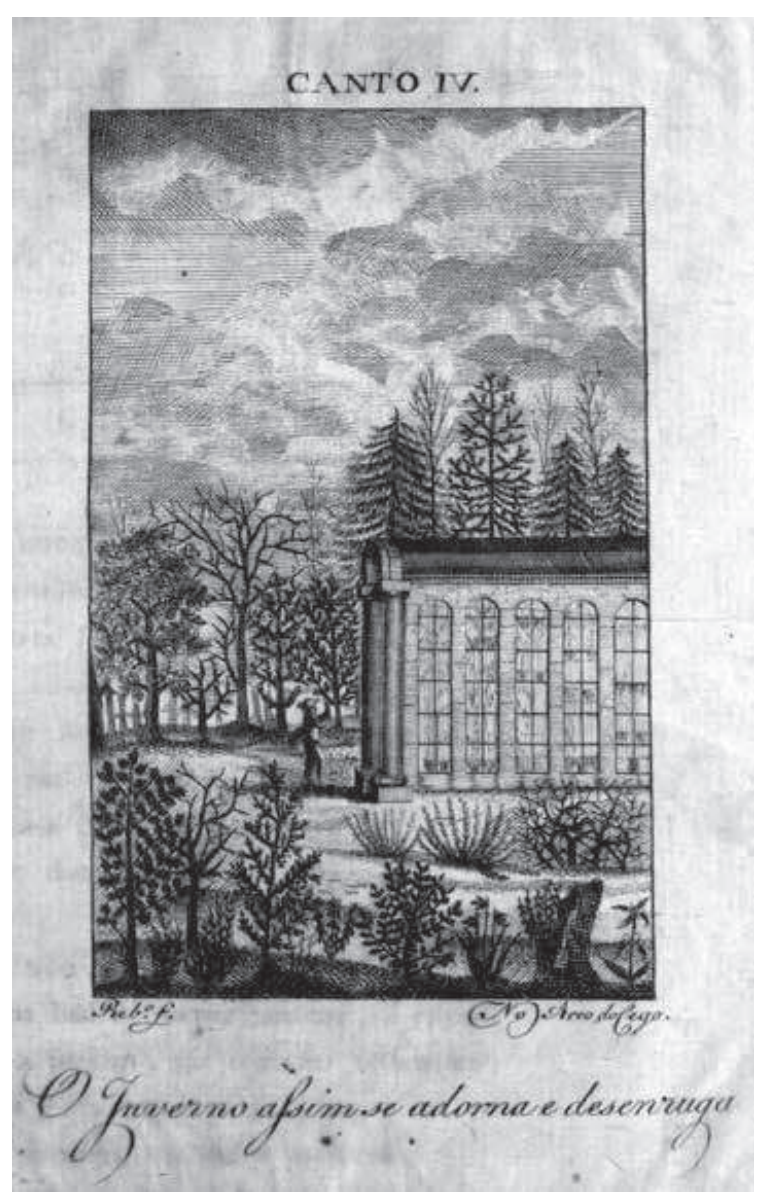
a legenda que segue abaixo da imagem trata das maravilhas sutis do inverno: " $\mathrm{O}$ inverno assim se adorna e se desenruga" (Castel, 1801, p. 165). Também são mencionados nesse último poema as viagens de James Cook (1728-1779). A expedição ao Círculo Polar Ártico comandada pelo capitão inglês é realçada por Castel como feito exemplar de domínio da natureza.

Figura 7. Romão Eloy de Almeida. "Canto IV". Calcogravura.

Tipografia Arco do Cego, 1801. Fonte: Biblioteca Brasiliana Guita e José Mindlin. 
Finalmente, Ricardo de Castel reverencia poetas e escritores que dedicaram seus versos ao mundo natural. Castel imagina um jardim em que estariam dispostas as estátuas de poetas como Delille, Hesiodo, Bernis, Saint-Lambert e Virgilio a conviver com as árvores, folhagens, animais e flores que tantas vezes foram cantadas em seus versos.

\section{CONSIDERAÇÕES FINAIS}

A descrição dessas estampas que ilustram os versos de Castel pode sinalizar o interesse da Oficina Arco do Cego em publicar livros destinados a instruir nos conhecimentos sobre as plantas e sobre a agricultura. Como já exposto, a linha editorial dessa tipografia segue as políticas implementadas pelo reinolusitano durante o século XVIII, alinhadas aos valores iluministas. Essas medidas privilegiavam a produção científica, e, em Portugal, nota-se um destaque aos estudos da história natural, com vistas a promover a produção agrícola, fundamentada em um aproveitamento eficiente dos recursos naturais.

A edição portuguesa do livro de Castel contribuiu com alguns ideais difundidos pelos intelectuais luso-brasileiros do século XVIII, pois, ao mesmo tempo em que a obra de Castel trata das formas de cultivo das plantas e dissemina o sistema de Lineu, seus versos procuram tornar esses saberes aprazíveis. Essa popularização das publicações científicas é marcante nas edições do período e objetivavam atingir um público amplo, entendendo a educação como um mote para o desenvolvimento econômico de uma nação. Para isso, as imagens têm papel decisivo "alas tinham uma forte carga informativa, ilustrativa, com fins de instruir, além de adornar os textos" (Pataca \& Schiavinatto, 2016, p. 561). A produção imagética procurava difundir descobertas científicas, propagar as técnicas agrícolas, instruir as práticas de coleta e transporte de plantas, entre outras funções. Nesse sentido, chama atenção o fato de a Oficina Arco do Cego ter escolhido publicar uma edição ilustrada da obra As Plantas, tendo em vista o elevado custo dessas edições e sabendo que nem todos os poemas didáticos editados por essa tipografia foram ilustrados. A partir do que foi exposto, pode-se concluir que as imagens que ilustram a edição portuguesa dos versos de Castel podem sinalizar aspectos fundamentais disseminados pela política portuguesa com aspirações iluministas. 


\section{REFERÊNCIAS}

Belluzzo, A. M. M. (1994). O Brasil dos viajantes. Salvador: Fundação Odebrecht.

Bernardo, L. M. (2013). Cultura Científica em Portugal: Uma Perspectiva Histórica. Porto: Editora Universidade do Porto.

Bosse, A. (1801). Tratado de Gravura a água-forte e a buril e em maneira negra com o modo de construir as prensas modernas e de imprimir em talho doce. Lisboa: Oficina Tipográfica, Calcográfica e Literária do Arco do Cego.

Castel. R. R. L. (1799). Les Plantes, poèmes. Paris: L'Imprimerie de Didot Jeune.

Cunha, L. F. F. (2010). A Oficina Tipográfica, Calcográfica e Literária do Arco do Cego. In Lyra, M. L. V.; Ribeiro, M. V. \& Santos, R. (orgs.). O acervo Iconográfico da Biblioteca Nacional: Estudos de Lygia da Fonseca Fernandes da Cunha. Rio de Janeiro: Fundação Biblioteca Nacional.

Daston, L. \& Galison, P. (2007). Objectivity. New York: Zone Books.

Dean, W.(1991). A Botânica e a política imperial: a introdução e a domesticação de plantas no Brasil. Rio de Janeiro: Estudos Históricos, 8(8), 216-228.

Diderot, D. \& D’Alembert, J. L. R. (1751). Encyclopédie ou dictionnaire raisonné des sciences des arts et des métiers. Paris: Edition Briasson.

Ferreira. O. C. (1994). Imagem e letra: Introdução à bibliografia brasileira a imagem gravada. São Paulo: EDUSP.

Harden, A. R. O. (2011). Os tradutores da Casa do Arco do Cego e a ciência iluminista: a conciliação pelas palavras. Trab. Ling. Aplic., Campinas, 50(2), 301-320.

Kury, L. (2004). Homens de ciência no Brasil: impérios coloniais e circulação de informações (1780-1810). Rio de Janeiro: História, Ciências, Saúde. Manguinhos, 11(1), 109-129.

Le Ménahèze, S. (2005). Ut pictura poesis non erit: les épisodes dans la poésie descriptive au xviiie siècle, Bélgica: L'information littéraire, 57(4), 15-22.

Lee, F. M. (2014). Instruir de maneira intensa e imediata: circulação e uso de estampas no Brasil joanino. Dissertação de Mestrado em História Social, São Paulo: Universidade de São Paulo.

Linnean Herbarium. Department of Phanerogamic Botany, Swedish Museum of Natural History. Recuperado: 20/12/2017. En línea http://linnaeus.nrm.se/botany/fbo/s/ sanic/sanieur.html.en

Marques, A. L. S. (2014). Arte, Ciência e História no Livro Português do Século XVIII. Doutorado em Belas Artes. Lisboa: Universidade de Lisboa.

Pataca, E. P. \& Schiavinatto, I. L. (2016). Entre imagens e textos: os manuais como práxis de saber. História, Ciências, Saúde. Manguinhos, 23(2), 551-566. 
Teute, J. F. (2000). The Loves of the Plants; or, the Cross-Fertilization of Science and Desire at the end of the Eighteenth Century. Huntington Library Quarterly. British Radical Culture of the 1790s, 63(3), 319-345.

Thomas, K. (2010). O homem e o mundo natural: mudanças de atitudes em relação às plantas e aos animais (1500-1800). São Paulo: Companhia das Letras.

Shirley Rodney. (2008). Allegorical images of Europe in someatlas titlepages, frontispieces, and map cartouches, Bélgica: Société Royale Belge de Géographie.

Veloso, José Mariano da Conceição (org.) (1806). Ofazendeiro do Brazil Criador. Lisboa: Imprensa Régia.

Wegner, R. (2004). Livros do Arco do Cego no Brasil colonial. História, Ciências, Saúde. Manguinhos, 11(1), 131-140.

\section{FONTE PRIMÁRIA}

Castel, R. (1801).As Plantas, poemas. Lisboa: Oficina tipográfica, calcográfica eliterária do Arco do Cego.

\section{IDENTIFICACIÓN DE LA AUTORA}

Maria de Fátima Medeiros de Souza é Doutoranda em Teoria e História da Arte, pelo Programa de Pós-Graduação em Arte da Universidade de Brasília. Mestra em Ciência da Informação (Biblioteconomia, Arquivologia e Museologia), pela Universidade de Brasília (2016). Graduada em Artes Plásticas, pela Universidade de Brasília (2009). Desenvolve pesquisas referentes ao livro de arte brasileiro e sobre a produção editorial ilustrada com gravuras. Bolsista da coordenação de aperfeiçoamento de pessoal de nivel superior (CAPES).

\section{REGISTRO BIBLIOGRAFFICO}

Medeiros de Souza, M. F. (2017). Imagens para instruir. Estudo das estampas que compõem a edição portuguesa do livro de poemas As Plantas, de Ricardo de Castel. InMediaciones de la Comunicación, 12(2), 31-47. 